\title{
Relation between Serum Pro-Brain Natriuretic Peptide, Myoglobin, CK Levels and Morbidity and Mortality in High Voltage Electrical Injuries
}

\author{
Murat Orak ${ }^{1}$, Mehmet Üstündağ ${ }^{1}$, Cahfer Güloğlu ${ }^{1}$, Şervan Gökhan ${ }^{2}$ and Ömer Alyan ${ }^{3}$
}

\begin{abstract}
Objective In our study, in addition to evaluating the relation between Pro-Brain natriuretic peptide (ProBNP), myoglobin and creatinine kinase (CK) levels and morbidity and mortality, we aimed at identifying the demographic characteristics of patients admited to emergency service after exposure to high electrical voltage.

Methods In this prospective study, 48 emergency service patients exposed to high electric voltage were included; 19 healthy individuals were included as the control group. Their blood samples and electrocardiographies (ECG) were taken at the time of recourse upon their written approval. Demographic data and laboratory data were checked and compared among the patient group. We investigated the correlation between inpatients that had special clinical manifestations (escaratomy, fasciotomy, exitus, myoglobulinuria, third-degree burn, arrhythmia and etc.) and serum Pro-BNP, myoglobin and CK levels.

Results When serum Pro-BNP, myoglobulin and CK levels were compared for the special clinical manifestations; the pro-BNP levels were statistically significantly higher in patients who had arrhythmia than in those without arrhythmia, and significantly higher in patients who died than in those who healed (respectively $\mathrm{p}=$ 0.002 and $\mathrm{p}=0.007$ ). In contrast, serum $\mathrm{CK}$ and myoglobin levels were not statistically significant. The serum $\mathrm{CK}$ and myoglobin levels were statistically significantly higher in patients who had third-degree burn than the others $(\mathrm{p}<0.001)$.

Conclusion Serum pro-BNP level is a marker that can be used for mortality and morbidity with patients exposed to high voltage electrical injuries.
\end{abstract}

Key words: brain natriuretic peptid, myoglobin, morbidity, mortality, high voltage electrical injury

(Intern Med 49: 2439-2443, 2010)

(DOI: 10.2169/internalmedicine.49.3454)

\section{Introduction}

Electrical current causes complex, unprecedented and unpredicted injuries (1). The term "high voltage" is often used for that over 1,000 volts. Yet evidence is available that seriousness and mortality risk in injuries increase as voltage increases over 600 volts. Electrical burns can be examined in a wide range of injuries starting from simple ones not requiring treatment to injuries causing loss of an extremity and even mortality. Serious tissue damage and mortality is caused by high voltage among all types of electrical burns (2).

Myoglobin, a 17,800 Dalton protein molecule consisting of 153 amino acids, is present only in heart and skeletal muscular tissue (3). Detectable myoglobin in the serum can be derived from either the cardiac muscle or the skeletal muscular system, or both. Physiologically, myoglobin is only detectable in low concentrations in serum or urine (4). Myoglobin serum level has been found to increase after extended muscular activity or even more after muscular injury (5-8).

${ }^{1}$ Emergency Department, University of Dicle, Diyarbakır, Turkey, ${ }^{2}$ Emergency Department, Education and Research Hospital of Diyarbakır, Diyarbakır, Turkey and ${ }^{3}$ Cardiology Department, University of Dicle, Diyarbakır, Turkey Received for publication January 27, 2010; Accepted for publication August 20, 2010 Correspondence to Dr. Murat Orak, drm.orak@dicle.edu.tr; m.orak21@mynet.com 
B-type natriuretic peptide (brain natriuretic peptide) is a neuro-hormone in the structure of peptide secreted from cardiac ventricles in response to volume and pressure load. In recent studies, it was reported that the pro-BNP level measured in plasma plays an important role in cardiovascular diseases, especially in the diagnosis and treatment of cardiac failure and acute coronary syndrome (9). If electric current courses through the heart, the efficiency of the heart will be affected and render worse cardiac pathology. The primary effect of electric current is on the cardiac conduction system and directly to myocardial cells. This effect can cause little necrosis at the myocardium and results in stress at ventricles and atriums (10). Ventricles are base sources for plasma BNP. Myocyte tension due to electric current provokes BNP release.

In the present study, in addition to evaluating the relation between serum Pro-BNP, myoglobin and creatinine kinase (CK) levels and morbidity and mortality, we aimed at identifying the demographic characteristics of patients admited to emergency service after exposure to high electrical voltage.

\section{Materials and Methods}

\section{Patients}

After receiving approval from the Chairmanship of the Board of Ethics of the Faculty of Medicine of Dicle University, 48 emergency service patients exposed to high electric voltage and who best fit the criteria of acceptance were included in this prospective study. As a control group, 19 volunteers healthy individuals who consented to be in the study were included in our study.

Patients who did not agree to be included in the study and also those with a history of comorbid disease (acute coronary syndrome, chronic ischemic heart disease, valvular heart disease, hypertension and cardio-myopathy, chronic heart failure, chronic pneumonia, etc.) which might effect pro-BNP and myoglobin levels were excluded from the study. Patients and/or their relatives were informed of the study. Their blood samples and electrocardiographies (ECG) were taken at the time of recourse upon their written approval. Blood samples taken were immediately transferred to the laboratory under appropriate conditions and test results were included in the study without delay. Pro-BNP concentrations were determined using a chemiluminescent immunoassay method (Immulite 2500; Siemens Medical Solutions, Holliston, MA, USA, with a reference level of 20-110 $\mathrm{pg} / \mathrm{mL}$ ). Myoglobin concentrations were also determined using a chemiluminescent immunoassay method (Immulite 2500; Siemens, with a reference level of 0-70 ng/mL) and CK concentrations were determined using a chemiluminescent immunoassay method (Architect C 8000, Abbott, USA, referrence interval 0-190 U/L).

In this study, their age, sex, vital findings, test findings (entry and exit of power localizations, burn degree, burn percentages due to Wallace's rule of nines), full blood tests, biochemistry, pro-BNP, CK and myoglobin levels, ECG findings, therapy applied (medical, escaratomy, fasciotomy) and their results were transferred into a form prepared by the researchers. Demographic and laboratory data were checked and compared among patient group individuals. We decided to investigate the correlation between inpatients that had special clinical manifestations (escaratomy, fasciotomy, exitus, myoglobulinuria, third-degree burn, arrhythmia and etc.) and serum Pro-BNP, myoglobin and CK levels.

\section{Statistical analysis}

Statistical analysis was carried out using chi-square test for categorical variables and Mann-Whitney $U$ test for permanent variables. For the statistical analysis, $\mathrm{p}<0.05$ was accepted as reasonable. Results were given as mean $\pm \mathrm{SD}$ or median; interquartile range.

\section{Results}

Patients had a mean age of $22.33 \pm 12.21$ years and 43 $(89.5 \%)$ of the patients were male, only $5(10.5 \%)$ were female. The control group had a mean age of $24.89 \pm 7.81$ and $11(57.8 \%)$ were male and $8(42.2 \%)$ of the control group were female. There was no statistically significant difference between patient and control groups with respect to age and sex. The average admission time to hospital was $4.63 \pm 3.87$ hours. The average length of stay in the hospital was $6.54 \pm$ 5.44 days. Table 1 shows the demographic characteristics of our patients.

In the patient group, electric current entry wounds are located mostly in the upper left extremity $62.5 \% \quad(n=30)$, $58.3 \%(n=28)$ upper right extremity, $4.1 \%(n=2)$ lower right extremity and $6.25 \%(n=3)$ on the body. Exit wounds were located in upper left extremity in $4.1 \%(n=2)$ of our patients, in the lower right extremity in $54.1 \%(n=26)$ and in lower left extremity in $45.8 \%(n=22) ; 4.1 \%(n=2)$ of patients suffered from first-degree burns, $83.3 \% \quad(n=40)$ second-degree burns and $60.4 \%(n=29)$ third-degree burns. The average systolic/diastolic blood pressure of patients was $114.3 \pm 12.3 / 72.0 \pm 8.4 \mathrm{mmHg}$ and the average systolic/diastolic blood pressure of controls was $110.8 \pm 8.5 / 71.3 \pm 7.8$ $\mathrm{mmHg}$. There was no statistically significant difference between patient and control groups with respect to systolic/diasytolic blood pressure. The average heart rate of patients was $90.7 \pm 14.5 / \mathrm{min}$ and the average heart rate of controls was $82.3 \pm 10.5 / \mathrm{min}$. There was statistically significant difference between patient and control groups with respect to heart rate $(\mathrm{p}=0.012) ; 56.3 \%(\mathrm{n}=27)$ patients had sinus tachycardia and, 29.1\% $(\mathrm{n}=14)$ had normal sinus rhythm; 7 patients had arrhythmia; 2 of them suffered from atrial fibrillation and 5 of them had ventricular premature systole. $93.75 \%(n=45)$ of patients were discharged with healing and $6.25 \%(n=3)$ of patients died (Table 1).

\section{Laboratory values}

Comparison of patients with respect to laboratory values 
Table 1. Demographic Data for Our Patients

\begin{tabular}{|c|c|}
\hline Characteristic & $\mathbf{n}$ \\
\hline \multicolumn{2}{|l|}{ Sex } \\
\hline Male & 43 \\
\hline Female & 5 \\
\hline Admission time (hours; mean \pm SD) & $4.63 \pm 3.87$ \\
\hline Age (years; mean \pm SD) & $22.33 \pm 12.21$ \\
\hline \multicolumn{2}{|l|}{ Electricity Entry Wound } \\
\hline Upper Left Extremity & 30 \\
\hline Upper Right Extremity & 28 \\
\hline Body & 3 \\
\hline Lower Right Extremity & 2 \\
\hline \multicolumn{2}{|l|}{ Electricity Exit Woumd } \\
\hline Lower Right Extremity & 26 \\
\hline Lower Left Extremity & 22 \\
\hline Upper Left Extremity & 2 \\
\hline \multicolumn{2}{|l|}{ Burn Degree } \\
\hline Second-degree Burn & 40 \\
\hline Third-degree Burn & 29 \\
\hline Total Burn Surface Area $(\% ;$ mean \pm SD) & $13.42 \pm 13.23$ \\
\hline \multicolumn{2}{|l|}{ Level of consciousness } \\
\hline Alert & 44 \\
\hline Stuporous & 3 \\
\hline Coma & 1 \\
\hline \multicolumn{2}{|l|}{ ECG Findings } \\
\hline Sinus Tachycardia & 27 \\
\hline Normal Sinus Rhythm & 14 \\
\hline Arrhythmia & 7 \\
\hline Length of stay in the hospital (days; mean \pm SD) & $6.54 \pm 5.44$ \\
\hline \multicolumn{2}{|l|}{ Result } \\
\hline Healed & 45 \\
\hline Exitus & 3 \\
\hline
\end{tabular}

is given in Table 2. Comparison of Pro-BNP, myoglobin and CK levels due to special clinical manifestation of electrical burn among patients is given in Table 3 .

Of our patients, $23 \%(\mathrm{n}=11)$ underwent escaratomy and $16.7 \%(\mathrm{n}=8)$ underwent fasciotomy. In $50 \%(\mathrm{n}=24)$, myoglobulinuria was positive, in $14.6 \%(n=7)$ had arrhythmia, $60.4 \%(n=29)$ had third-degree burns and $6.25 \%(n=3)$ of patients died. When serum Pro-BNP, myoglobulin and CK levels were compared for these special clinical manifestations; the pro-BNP levels were statistically significantly higher in patients who had arrhythmia than those without arrhythmia, and significantly higher in patients who died than in those who were healed (respectively $\mathrm{p}=0.002$ and $\mathrm{p}=$ 0.007). In contrast, serum $\mathrm{CK}$ and myoglobin levels were not statistically significant (Table 3). When serum Pro-BNP, CK-MB and TPI levels were compared in patients who had arrhythmia or not, the pro-BNP levels were statistically significantly higher in patients who had arrhythmia than in those without arrhythmia $(\mathrm{p}=0.002)$. But serum CK-MB and TPI levels were not statistically significant $(\mathrm{p}=0.785$ and $\mathrm{p}=$ 0.632 , respectively). The serum $\mathrm{CK}$ and myoglobin levels were statistically significantly higher in patients who had third-degree burn than in the other burn patients $(\mathrm{p}<0.001)$ (Table 3).

\section{Discussion}

Electrical injuries can be defined as occupational trauma (11). The true incidence of electrical accidents is not known. Although the frequency of non-serious electrical shocks is not known, approximately over 17,000 victims are admitted in emergency services in the United States (USA) annually (12). In US $0.8-1 \%$ of accidental deaths are caused by electrical injuries $(2,11)$.

High voltage electrical injuries often occur in the upper extremities. Since hands are used when working, playing, climbing or holding any object, the upper extremities are exposed to electrical current in a rate as high as $70-80 \%$ (11). Generally entry is an upper extremity and exit is a lower extremity (13). In recent studies (14), the typical current pathway is from upper through lower extremity (15). Similarly, in the present study the entry was generally located in the upper extremities and the exit was located in lower extremities.

Electrical injuries may cause various abnormalities from disrhythmias to myocardial infarct. Cardiac abnormality incidences following electrical injury were found between $15 \%$ and $54 \%$ in different series (16-18). Most of these studies are high voltage injury studies (18). Sinus tachycardia, premature atrial contractions, premature ventricular contractions, supraventicular tachycardia, arterial fibrillation, first and second degree AV blocks were observed in more than $30 \%$ high voltage electrical injuries (2). In $56.3 \%$ of our patients sinus tachycardia and in $14.6 \%$ arrhythmia was observed. Pro-BNP level was higher in patients with cardiac transmission failure than in those who did not develop cardiac transmission failure, and this value was statistically significant.

The muscle necrosis in electrical injuries is related to massive myoglobulinuria due to large amounts of myoglobin that is usually seen in similar crush type injuries (11). If at the same time, dehydratation is also present, this causes injury by gathering in kidneys leading to acute renal failure (11). Although the myoglobin incidence changes between $14-42 \%$ after electrical injury, it can rise to $75-100 \%$ due to exposure to high voltage (19). In $50 \%$ of our cases myoglobulinuria was present. Rosen et al, in their study, indicated that myglobulinuria can be used in pre-identifying, dismissing those of frivolous risk, and separating high risk patients with myoglobulinuria who need urgent treatment. In the same study myoglobulinuria was seen to be a marker for morbidity (19). Also in the present study, Pro-BNP, myoglobin and CK levels were found to be higher in patients who have myoglobulinuria when compared to those who do not have myoglobulinuria. This was found to be statistically significant. Pro-BNP, myoglobin and CK also can be used as a marker for morbidity. 
Table 2. Median Values of Biochemical Parameters for Patient and Control Groups

\begin{tabular}{lccc}
\hline & Control Group & Patient Group & p value \\
& $\mathbf{n = 1 9}$ & $\mathbf{n = 4 8}$ & \\
\hline WBC (K/UL;Median(Interquartile range)) & $10500(7490-12600)$ & $17000(14650-21425)$ & $<0.001$ \\
ALT (U/L;Median(Interquartile range)) & $12.83(9.60-22.00)$ & $63.50(22.62-194.75)$ & $<0.001$ \\
AST (U/L;Median(Interquartile range)) & $17.05(13.30-21.90)$ & $93.22(38.82-329.90)$ & $<0.001$ \\
Glucose (mg/dL;Median(Interquartile range)) & $98.00(82.9-104.5)$ & $125.50(109-162.7)$ & $<0.001$ \\
CK (U/L;Median(Interquartile range)) & $134.00(50-345)$ & $2759.50(712-12803)$ & $<0.001$ \\
CKMB (U/L;Median(Interquartile range)) & $23.00(12-31)$ & $115.00(49.5-233.8)$ & $<0.001$ \\
Troponin I (ng/mL;Median(Interquartile range)) & $0.10(0.1-0.24)$ & $0.53(0.26-0.98)$ & $<0.001$ \\
Pro-BNP (pg/mL;Median(Interquartile range)) & $37.20(22.5-72.8)$ & $236.55(135.8-508.8)$ & $<0.001$ \\
Myoglobin (ng/mL; Median(Interquartile range)) & $59.0(45.0-69.0)$ & $922.0(472.2-1166.0)$ & $<0.001$ \\
\hline
\end{tabular}

Table 3. Median Pro-BNP, Myoglobin and CK Levels in Special Clinical Manifestations

\begin{tabular}{|c|c|c|c|c|c|c|c|}
\hline & $\mathbf{n}$ & $\begin{array}{c}\text { Pro-BNP } \\
\text { (pg/mL;Median } \\
\text { (Interquartile range)) }\end{array}$ & $\mathbf{p}$ & $\begin{array}{c}\text { Myoglobin } \\
\text { (ng/mL; Median } \\
\text { (Interquartile range)) }\end{array}$ & $\mathbf{p}$ & $\begin{array}{c}\text { CK } \\
\text { (U/L;Median } \\
\text { (Interquartile range)) }\end{array}$ & $\mathbf{p}$ \\
\hline \multicolumn{8}{|l|}{ Escaratomy } \\
\hline Present & 11 & $871(306-1400)$ & $<0.001$ & $971(971-1287)$ & 0.013 & 12777(1919-20000) & 0.054 \\
\hline Absent & 37 & $174(98-312)$ & & $560(430-1126)$ & & $1530(525-8641)$ & \\
\hline \multicolumn{8}{|l|}{ Fasciotomy } \\
\hline Present & 8 & $923(179-1445)$ & 0.032 & $948(572-1276)$ & 0.406 & $10845(1089-2000)$ & 0.306 \\
\hline Absent & 40 & 221(119-379) & & $843(458-1166)$ & & $2759(578-11034)$ & \\
\hline \multicolumn{8}{|l|}{ Exitus } \\
\hline Present & 3 & $1472(1400-1545)$ & 0.007 & $1326(926-1326)$ & 0.053 & $20000(1690-20000)$ & 0.143 \\
\hline Absent & 45 & $229(129-411)$ & & $768(458-1135)$ & & $2727(586-12167)$ & \\
\hline \multicolumn{8}{|c|}{ Myoglobulinuria } \\
\hline Present & 24 & $349(184-970)$ & 0.003 & $1126(966-1275)$ & $<0.001$ & $12794(2743-20000)$ & $<0.001$ \\
\hline Absent & 24 & $167(80-251)$ & & $485(382-548)$ & & $1128(301-2550)$ & \\
\hline \multicolumn{8}{|c|}{ Third-degree Burn } \\
\hline Present & 29 & $290(154-758)$ & 0.242 & $512(370-560)$ & $<0.001$ & $9463(1804-20000)$ & $<0.001$ \\
\hline Absent & 19 & $160(84-357)$ & & $1067(724-1248)$ & & $1043(238-2573)$ & \\
\hline \multicolumn{8}{|l|}{ Arrhythmia } \\
\hline Present & 7 & $654(500-1003)$ & 0.002 & 1142(918-1276) & 0.074 & $2792(570-15510)$ & 0.819 \\
\hline Absent & 41 & $208(113-312)$ & & $680(444-1126)$ & & $2727(822-12167)$ & \\
\hline
\end{tabular}

High voltage injuries are devastating injuries with constant high compartment syndrome. Vascular compression and thrombosis may cause secondary ischemic necrosis which may result in both upper and lower extremity amputation (20). Although it was not statistically significant that early fasciotomy saves organs in patients having $40 \%$ less than total body burn after high voltage burn, it should be emphasized that early muscle compartment decompression within 4-6 hours provided great value in preventing tendency towards muscular necrosis (21). Measured pro-BNP levels of patients treated with escaratomy or fasciotomy were found to be higher than non-treated patients. This result was also statistically significant. Therefore, it can be used as a marker for morbidity with high pro-BNP level.

The most frequent reason for mortality related to electric injuries is cardiac. While low voltage injuries cause ventricular fibrillation, temporary ventricular asystole can be formed due to high power alternating current and direct cur- rent (2). Mortality rates differ between $2-15 \%$ in different series (15). In the study carried out by Ferreiro et al, they found that mortality rate directly related to the presence of secondary cranial injury due to respiratory and trauma was $12 \%$ in patients with $90 \%$ burns (15). In the present study, the mortality rate was found to be $6.25 \%$. These deaths were reported to be due to sepsis which developed in the burn unit. The pro-BNP levels of these cases were significantly high.

\section{Limitations}

Our study is based on a single department and patient numbers may be considered as inadequate for this research. Blood pro BNP, myoglobin and CK levels were not evaluated on subsequent days. Multicenter studies with many more electric injuried patients must be planned. 


\section{Conclusion}

Pro-BNP value was high in high voltage electrical injury patients in whom cardiac transmission failure and myoglobulinuria improved, as compared with those who underwent fasciotomy and escaratomy and those with exitus. Consequently, pro-BNP value can be considered a marker that can be used for mortality and morbidity in patients exposed to high voltage electrical injuries.

\section{References}

1. Billowitz EB. Electrical injuries. In: Principles and Practice of Emergency Medicine. 4th ed. Schwartz GR, Roth PB, Cohen JS, Eds. Lippincott Williams Wilkins, Baltimore, Maryland, 1999: 1399-1405.

2. Güloğlu C, Orak M, Altunci YA. Electric injury and burns. Turkiye Klinikleri J Surg Med Sci 3: 84-88, 2007 (in Turkish).

3. Hofmann D, Buettner M, Rissner F, Wahl M, Sakka SG. Prognostic value of serum myoglobin in patients after cardiac surgery. J Anesth 21: 304-310, 2007.

4. Mair J, Artner-Dworzak E, Lechleitner P, et al. Early diagnosis of acute myocardial infarction by a newly developed rapid immunoturbidometric assay for myoglobin. Br Heart J 68: 462-468, 1992.

5. Holt SG, Moore KP. Pathogenesis and treatment of renal dysfunction in rhabdomyolysis. Intensive Care Med 27: 803-811, 2001.

6. Laurence AS. Serum myoglobin and serum creatine kinase following surgery. Br J Anaesth 84: 763-766, 2000.

7. Koz M, Erbaş D, Bilgihan A, Aricioğlu A. Effects of acute swimming exercise on muscle and erythrocyte malondialdehyde, serum myoglobin and plasma ascorbic acit concentrations. Can J Physiol Pharmacol 70: 1392-1395, 1992.

8. Fricke P, Weiss G, Lippert H. Ischemia/reperfusion syndromemyoglobin: its impact and role as a prognostic parameter. A retrospective analysis of clinical data. Intensivmedizin 39: 38-46, 2002 (in German).

9. Duygu H, Türk Ü, Zoghi M, Nalbantgil S. The importance of plasma B-type natriuretic peptide levels in cardiovascular diseases. Anadolu Kardiyol Derg 5: 305-311, 2005 (in Turkish).

10. Uzkeser M, Aksakal E, Aköz A, Aslan S, Emet M, Çakır Z. Atrial fibrillation due to electrocution. Akademik Acil Tip Dergisi 8: 3840, 2009 (in Turkish).

11. Dalay C, Elektrik Yanıkları, Ertekin C, Taviloglu K, Güloglu R, Kurtoglu M. Travma. İstanbul Medikal Yayıncılık Ltd. sti. İstanbul, 2005: 594-602 (in Turkish).

12. Fish RM. Electrical injuries. In: Emergency Medicine: a Comprehensive Study Guide. 6th ed. Tintinalli JE, Kelen GD, Stapczynski JS, Eds. The McGraw-Hill, New York, 2004: 1231-1235.

13. Docking P. Electrical burn injuries. Accid Emerg Nurs 7: 70-76, 1999.

14. Burke JF, Quinby WC Jr, Bondoc C, McLaughlin E, Trelstad RL. Patterns of high tension electrical injuries in children and adolescents and their management. Am J Surg 133: 492-497, 1977.

15. Ferreiro I, Meléndez J, Regalado J, Béjar FJ, Gabilondo FJ. Factors influencing the sequelae of high tension electrical injuries. Burns 24: 649-653, 1998.

16. Purdue GF, Hunt JL. Electrocardiographic monitoring after electrical injury: necessity or luxury. J Trauma 26: 166-167, 1986.

17. Chandra NC, Siu CO, Munster AM. Clinical predictors of myocardial damage after high voltage electrical injury. Cvificnl Cave Medicine 18: 293-297, 1990.

18. Arrowsmith J, Usgaocar RI, Dickson WA. Electrical injury and the frequency of cardiac complications. Burns 23: 576-578, 1997.

19. Rosen CL, Adler JN, Rabban JT, et al. Early predictors of myoglobinuria and acute renal failure following electrical injury. $\mathrm{J}$ Emerg Med 17: 783-789, 1999.

20. Garcia-Sánchez V, Gomez Morell P. Electric burns: high- and lowtension injuries. Burns 25: 357-360, 1999.

21. Koop J, Loos B, Spilker G, Horch RE. Correlation between serum creatinine kinase levels and extent of muscle damage in electrical burns. Burns 30: 680-683, 2004.

(C) 2010 The Japanese Society of Internal Medicine http://www.naika.or.jp/imindex.html 